\title{
The Impact of Physiological Features on External Anal Sphincter Electromyography
}

Lei Zhao, Hua Du, Benhong Li, Shuang Wu, Nan Lin and Liying Cui ${ }^{*}$

Department of Neurology, Peking Union Medical College Hospital, Beijing, China

"Corresponding author: Liying Cui, Department of Neurology, Peking Union Medical College Hospital, Neuroscience Center,Chinese Academy of Medical Science, Beijing, China, Tel: +86-010-65296372; Fax: +86-010-65296371; E-mail: pumchcuily@yahoo.com

Received date: June 25, 2014, Accepted date: Sep 06, 2014, Published date: Sep 15, 2014

Copyright: (c) 2014 Zhao L, et al. This is an open-access article distributed under the terms of the Creative Commons Attribution License, which permits unrestricted use, distribution, and reproduction in any medium, provided the original author and source are credited.

\begin{abstract}
Objective: To explore the impact of physiological factors, such as age, gender, and childbirth experience, on external anal sphincter electromyography.

Methods: A total of 62 healthy volunteers (37 women and 25 men) participated in the study.The female subjects were divided into three groups according to various childbirth experiences: the nulliparous group, the caesarean group, and the vaginal delivery group. Motor unit potentials were obtained from the bilateral external anal sphincter of each subject using multi-MUP analysis. The mean values of each parameter (including duration, amplitude, area, mean number of turns, mean number of phases, and satellite rate) were calculated for each subject. The impact of age, gender, and childbirth experience on the parameters of the anal sphincter electromyography were analyzed statistically.
\end{abstract}

Results: The mean durations were longer and the satellite rates were higher in the vaginal delivery group than in the nulliparous or caesarean groups. There were no significant differences in any of the electromyography parameters between the nulliparous and caesarean groups. None of the electromyography parameters changedsignificantlywith increases in vaginal delivery times. A multiple linear regression analysis of each electromyography parameter for age, gender, and vaginal delivery experience indicated that gender and vaginal delivery experience influenced the parameter of duration; vaginal delivery experience also influenced the parameter of satellite rate; and age did not significantly affect any of the parameters except the number of phases.

Conclusion: Age, gender, and vaginal delivery experience impact differently on the various anal sphincter electromyography parameters. These variables should be taken into consideration when interpreting electromyography results in clinical work.

Keywords: External anal sphincter; Needle electromyography; Motor unit potential; Satellite potential; Gender; Age; Childbirth

\section{Introduction}

The external anal sphincter is innervated by Onuf's nucleus, which is located in the anterior horn of the spinal cord at the S2 level [1-5] through the pudendal nerve. Lesions of Onuf's nuclei and the roots of the sacral and pudendal nerves could be displayedby the external anal sphincter electromyography (EMG), an important neurophysiological method widely used by neurologists, orthopedists, and urologists.

Compared with the other motor neurons of the anterior horn of the spinal cord and limb muscles, the neurons in Onuf s nuclei and the external anal sphincter consist of unique characteristics(1) although it belongs to the somatic system, Onuf's nucleus has some automatic feature [6]; (2) sexual dimorphismhas been observed [7-9], and therefore, some perineal muscles innervated by Onuf's nuclei, namely, the bulbocavernosus and schiocavernosus muscles, are only present in males, and males have significantly more motor neurons in Onuf's nucleus than females. The development of this sexual dimorphism was thought to be caused by the effect of androgen; (3) the external anal sphincter is always in a state of tonic contraction, which reduces only during activerelaxation. Besides beinga support for the abdominal and pelvic contents againstgravity, the external anal sphincter and its innervation are prone to damage in daily life and in particular physiological processes, such as pregnancy and delivery. Therefore, the crucial questions areas follows: do the physiological features of age, gender, and childbirth experience have an impact on the external anal sphincter EMG? If so, which parameter of the EMG is influenced by each physiological factor and to what degree?

As a result of the external anal sphincter EMG is the summation of pathological lesions and physiological effects, it is imperative to explore the effect of physiological factors on the external anal sphincter EMG for its reasonable application in clinical work. In this study, we analyzed the physiological features of gender, age, and childbirth experienceon the parameters of the external anal sphincter EMG in a healthy population.

\section{Subjects and Methods}

\section{Subjects}

A total of 62 healthy volunteers participated in the study. Subjects without a history of neurological disease, complaints of urinary or defecation abnormalities, and with normal results from a neurological 
examination (including mental status, the cranial nerve, muscle force, muscle tone, tendon reflex, senses, coordination of movement, and gait) were included. Among the 62 subjects, 25 were men; among the 37 women, 9 were nulliparous (NU), 7 had experienced caesarean (CA), and 21 had uncomplicated vaginal delivery (VA) experiences (12 women had one VA;6 women had two; and 3 womenhad 3).The study was approved by the Ethics Committee of Peking Union Medical College Hospital (PUMCH), and all subjects gave written informed consent.

\section{Methods}

A 37-mm-long standard concentric EMG needle with a recording area of $0.07 \mathrm{~mm} 2$ (Medelec, UK) and a Medtronic Keypoint Electromyography system (Dantec Medical, Denmark) were used. The settings were as follows: filters $(20 \mathrm{~Hz}-10 \mathrm{kHz})$, gain $(100 \mu \mathrm{V} /$ div $)$, and sweep ( $5 \mathrm{~ms} / \mathrm{div}$, adjusted manually to include the extra potentials as no existing software is capable of differentiating them) (Figure 1). A multi-MUP (motor unit potential) analysis was used [10,11]. The subjects laiedon their left side with hips and knees flexed. The position of needle insertion was 3:00 and 9:00 $1 \mathrm{~cm}$ outward from the anal orifice(Figure 2). At least 20 MUPs were gathered bilaterally from the subcutaneous part of the external anal sphincters, with or without the deeper part for each subject $[12,13]$. The manual adjustment and deletion of the waves were approved. Satellite potentials, defined as small extra potentials preceding/following the main MUP component in a time-locked relationship and separating from it by an almost isoelectrical interval of at least $1 \mathrm{~ms}$ [14] were included in the duration measurement (Figure 1). MUPs were deleted manually if they were found to be duplicates, if they automatically identified as having dissimilar wave shapes at each firing or as nothing but a extra potential of one MUP (i.e., satellite potentials), or if they had unsteady baselines (without defined duration boundaries) or amplitudes below $50 \mu \mathrm{V}$. The parameters included duration, amplitude, area, number of phases,number of turns, and satellite rate.

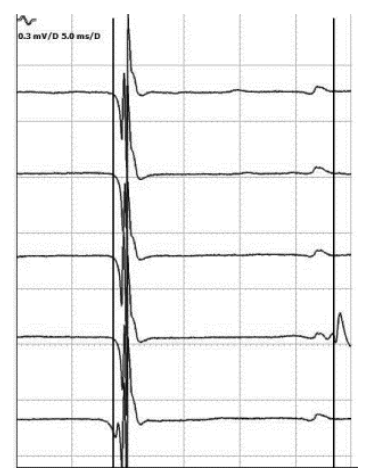

Figure 1(a): An MUP with a satellite potential sample obtained from a 48-year-old woman withthe experience of vaginal delivery. (A) The MUP firing raster showed the extrapotential time-locked to the main MUP component with an isoelectric interval ofabout 13 $\mathrm{ms}$, which suggested a satellite potential.

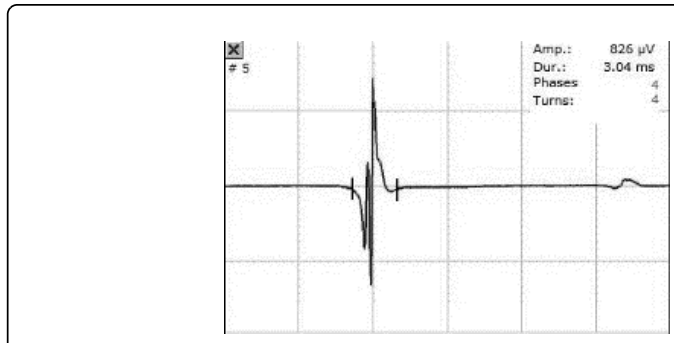

Figure 1(B): The duration measuredautomatically.

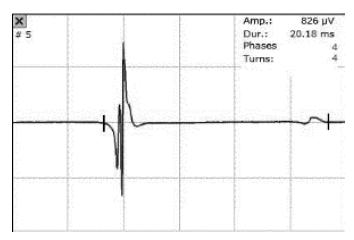

Figure 1(C): Manual adjustment to include the satellite potential.

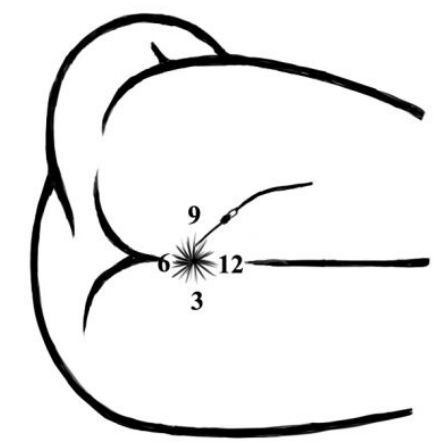

Figure 2: Schematic representation of the position of needle insertion.

\section{Statistical analysis}

The satellite rate (the number of MUPs with satellite potentials divided by the total number of MUPs) and the mean values of each MUP parameter were calculated for each subject. The distributions of the parameters were tested by the Shapiro-Wilks W test for normality and the Levene test for homogeneity of variance. The parameters with a normal distribution between the groups of each delivery type(NU, $\mathrm{CA}$, and VA) were tested by one-way ANOVA with the Bonferroni correction for multiple comparisons. The parameters between the subjects who had undergone different numbers of vaginal deliveries (1-3) were compared using the Kruskal-Wallis ANOVA because of the limited samples in each group. The exact impact factor of childbirth on the external anal sphincter EMG was then determined. Afterwards, a linear regression analysis of each EMG parameter using the mean values of each subject was performed for age, gender, and the determined factor of childbirth. 


\section{Results}

The mean age of the 62 subjects was 41.9 (20-62) years. All the data on the parameters for each group of childbirth type were consistently normally distributed with equal variances. Using the one-way ANOVA, the durations, mean numbers of phases, and satellite rates between each group according to childbirth type were significantly different. Further multiple comparisons showed that the mean durations were longer and the satellite rates were higher in the VA group than in the $\mathrm{NU}$ or $\mathrm{CA}$ groups. Moreover, there were no significant differences in any of the parameters between the NU and CA groups (Table1, Figure3). The impact of the number of vaginal deliveries on the external anal sphincter EMG was also analyzed by the Kruskal-Wallis non-parametric ANOVA, and none of the parameters showed statistically significant differences (Figure 4). The data illustrated that the experience of vaginal delivery had an explicit impact on the external anal sphincter EMG parameters, which was considered to be strongly correlated with the vaginal delivery process rather than that of pregnancy itself. In addition, the impact on the EMG parameters was mainly associated with the first vaginal delivery experience. The exact factor of vaginal delivery experiencealong with age and gender were included in a multiple linear regression analysis, which indicated that gender and vaginal delivery experience influenced the MUP parameter of duration; that vaginal delivery experience also influenced the parameter of satellite rate; and that age did not significantly affect any MUP parameter except for the number of phases (Table 2).

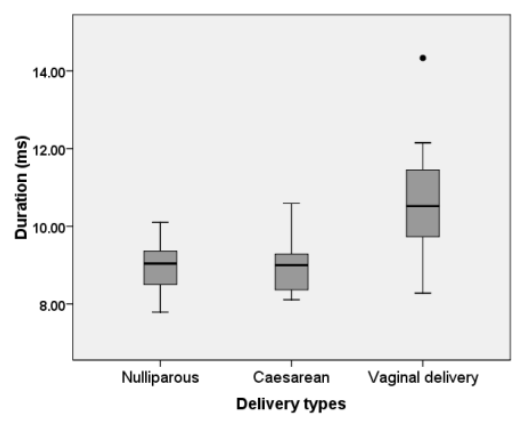

Figure 3(a): Mean durations and satellite rates of groups according to various delivery types.

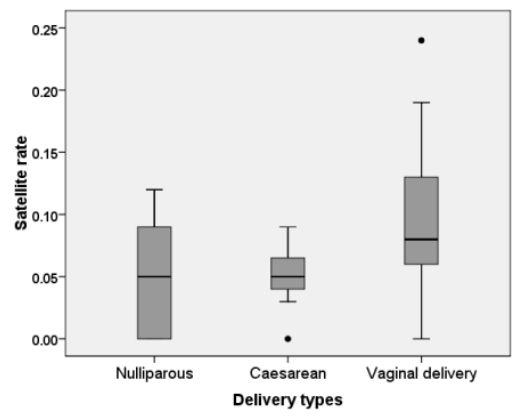

Figure 3(b): Mean durations and satellite rates of groups according to various delivery types.

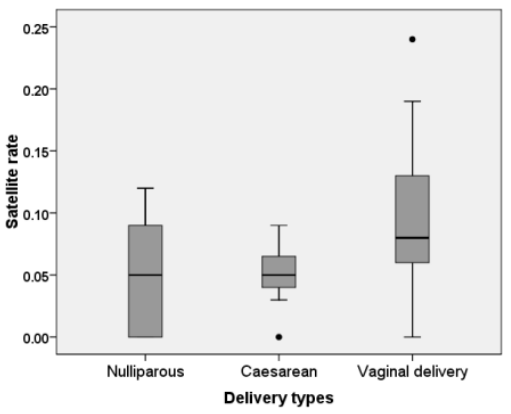

Figure 4(a): Mean durations and satellite rates of groups according to the number of vaginaldeliveries.

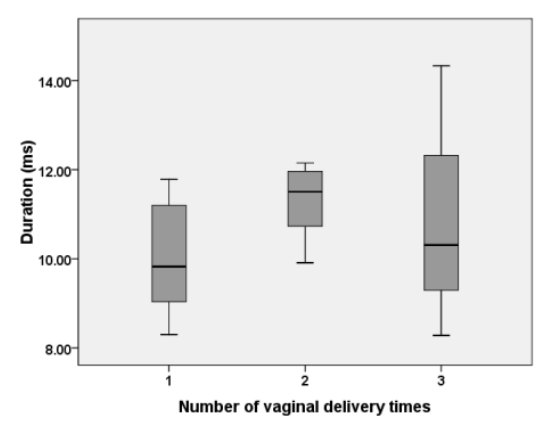

Figure 4(b): Mean durations and satellite rates of groups according to the number of vaginaldeliveries.

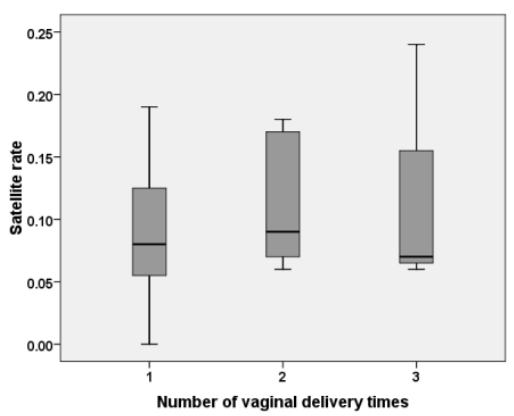

Figure 4(c): Mean durations and satellite rates of groups according to the number of vaginaldeliveries.

\begin{tabular}{|l|l|l|l|l|l|l|}
\hline $\begin{array}{l}\text { Impact } \\
\text { factor }\end{array}$ & Amp. & Dur. & Turns & Phases & Area & $\begin{array}{l}\text { Satellite } \\
\text { Rate }\end{array}$ \\
\hline Gender & 0.925 & 0.019 & 0.395 & 0.384 & 0.058 & 0.887 \\
\hline Age & 0.483 & 0.224 & 0.186 & 0.007 & 0.432 & 0.769 \\
\hline Parity & 0.336 & 0.002 & 0.271 & 0.129 & 0.881 & 0.014 \\
\hline
\end{tabular}

Table 2: $\mathrm{P}$ values of multiple linear regression analysis presenting the effect of age, gender, and vaginaldelivery experience on EMG 
Page 4 of 6

parameters; Amp., amplitude; Dur., duration. Significant $\mathrm{P}$ values $(<0.05)$ are in bold print.

\section{Discussion}

\section{The impact of childbirth on EAS EMG}

As far as childbirth experience was concerned, caesarean and pregnancy had no impact on the external anal sphincter EMG, and the process of vaginal deliverymight have influenced the innervation of the external anal sphincter due to the squeezing of the fetus through the birth canal. In addition, the injury was not superimposed by increasing numbers of vaginal deliveries. The duration was longer and the satellite rate was higher in women with vaginal delivery experience, which indicated the re-innervation of the external anal sphincter after the injury.

The impact of vaginal delivery on the innervationof the external anal sphincter has been thoroughly demonstrated and was thought to be closely correlated withfecal incontinence. The long second stage of labor, heavier babies, and forceps delivery were thought to be the risk factors associated with vaginal delivery injury [15-19]. Gregory [20] alsofound injury in asymptomatic womenafter uncomplicated vaginal deliveries. In addition, Allen [16] and Boyle [19] indicated the importanceof the first experience on the external anal sphincter EMG.

The external anal sphincter is innervated by Onuf's nucleus through the pudendal nerve, which crosses the apex of the ischiorectal fossa and runs on the perineal surface of the levatorani. This anatomical relationship maybe the reason of the pudendal nerve's susceptibility to vaginal delivery $[3,21,22]$.

\section{The impact of age on external anal sphincter EMG}

In our study, the mean phases were positively correlated with age while the other parameters showed no statistical relation. This suggests an age-related physiological change, that is, MUP complexity increases with aging.

In a cytoarchitectonic study, the number of neurons in the anterior horn of the spinal cord was noted to decrease with aging [23] and was more prominent after 60 years [24].Significant age-associated declines of the innervation Onuf's nucleus were also found in an animal study [25]. In an electrophysiological study, Laurberg and his colleagues[26] found that the pudendal nerve terminal motor latency (PNTML) period initially increased in the fourth decade of life and was followed a decade later by an increase in the SFEMG fiber density in the external anal sphincter muscle.Moreover, there was inevitabledaily life wear and tear in the external anal sphincter muscle. These factors might explain the increased number of phases accompanied by aging.

Except for the number of phases, other parameters, including duration, were found to be uncorrelated with aging. The possible explanations are as follows: first, as mentioned above, the age-related change was prominent after 60 years [24] while there were only four subjects over 60 years of age in our study, which might make the change unobvious. The second explanation is related to cancellation [27]. The muscle fibers of the external anal sphincter were tiny, and the effect of cancellation was much more explicit, which resulted in a higher number of phases and turns compared to a less sensitive duration. The third is related to the full compensation of the motor unit of the external anal sphincter in healthy subjects.

\section{The impact of gender on external anal sphincter EMG}

Men tend to have a larger motor unit potential than women. Besides the possibility of the sexual dimorphism of Onuf's nuclei [7-9], previous studies found the size of muscle fibers to be larger in males than in females [28], which might explain the gender differences.

\section{The external anal sphincter EMG data should be interpreted cautiously in clinical studies}

Our data indicated the influence of age, gender, and childbirth experience onthedifferent parameters of the externalanal sphincter EMG. As the external anal sphincter EMG is the summation of pathological lesions and physiological effects, similar EMG manifestation might result from pathological lesions or just physiological effects, or both. Tison's [29] study indicated a threshold of $13 \mathrm{~ms}$ of MUP duration was highly sensitive (80\%) and rather specific (70\%) for the diagnosis of multiple system atrophy (MSA) although later studies have not been able to confirm this [30,31]. In our study, mean MUP duration over $13 \mathrm{~ms}$ was shown in one women $(14.3 \mathrm{~ms})$ with three times of vaginal delivery experience while none in men and women without vaginal delivery experience, which indicated a false positive of external anal sphincter EMG due to vaginal delivery. In fact, Tison had also noticed the impact of physiological features and past histories on external anal sphincter EMG in his study and suggested taking into account the influence of age, gender, parityand history ofpelvic surgery, his opinion was fully consistent with our study. Thus causious interpretation of the data was indispensable in EMG studies, impartial judgments needed the combination of disorders associated clinical signs, physiological features and past histories. In some cases, the combination of other additional diagnostic tests (PNTML, anal manometry, urodynamic, and imaging studies, et. al) might be more effectively in the interpretation of the EMG data.

One limitation of this study is that the mean age was not matched between groups of different childbirth experiences (Table 1). This was consistent with the general and rational social phenomenon that nulliparous women were usually younger than parous women. In terms of the private site of the external anal sphincter, the number of volunteers was limited, and it was very difficult to produce matches between the groups of different childbirth experiences on the basis of age. Theresult of the multi-linear regression analysis of age, gender, and vaginal delivery indicated the same result as the ANOVA, which was nottheoretically influencedby the mismatch in age.

\begin{tabular}{|c|c|c|c|c|c|c|c|c|c|c|c|c|c|c|}
\hline \multirow[t]{2}{*}{ Groups } & \multirow[t]{2}{*}{$\mathbf{N}$} & \multirow[t]{2}{*}{ Age } & \multicolumn{2}{|c|}{$\operatorname{Amp}(\mu \mathrm{V})$} & \multicolumn{2}{|c|}{ Dur (ms) } & \multicolumn{2}{|c|}{ Number of turns } & \multicolumn{2}{|c|}{$\begin{array}{l}\text { Number } \\
\text { phases }\end{array}$} & \multicolumn{2}{|c|}{ Area $(\mu \mathrm{Vms})$} & \multicolumn{2}{|c|}{ Satellite Rate } \\
\hline & & & mean & SD & mean & SD & mean & SD & mean & SD & mean & SD & mean & SD \\
\hline Total & 62 & 41.9 & 533.41 & 87.41 & 9.92 & 1.31 & 3.72 & 0.49 & 3.84 & 0.39 & 474.17 & 122.92 & 0.07 & 0.05 \\
\hline
\end{tabular}




\begin{tabular}{|c|c|c|c|c|c|c|c|c|c|c|c|c|c|c|}
\hline Male & 25 & 43.2 & 546.39 & 71.52 & 10.05 & 1.07 & 3.75 & 0.49 & 3.86 & 0.41 & 517.13 & 148.45 & 0.05 & 0.05 \\
\hline Female & 37 & 41.0 & 524.63 & 96.64 & 9.84 & 1.46 & 3.70 & 0.49 & 3.84 & 0.38 & 445.15 & 93.60 & 0.08 & 0.06 \\
\hline VA & 21 & 46.0 & 515.00 & 78.27 & 10.52 & 1.51 & 3.82 & 0.48 & 3.98 & 0.31 & 442.41 & 88.11 & 0.10 & 0.06 \\
\hline $\mathrm{CA}$ & 7 & 45.3 & 572.03 & 138.16 & 9.00 & 0.85 & 3.46 & 0.29 & 3.60 & 0.37 & 479.67 & 117.31 & 0.05 & 0.03 \\
\hline $\mathrm{NU}$ & 9 & 26.2 & 510.25 & 99.79 & 8.91 & 0.73 & 3.61 & 0.58 & 3.70 & 0.44 & 424.69 & 90.36 & 0.05 & 0.05 \\
\hline
\end{tabular}

Table 1: Means and standard deviations of the external anal sphincter EMG parameters for each group; VA, vaginal delivery; CA, caesarean; NU, nulliparous; Amp., amplitude; Dur., duration.

\section{Conclusion}

Our data indicated that age, gender, and childbirth experience do influence the different parameters of the external anal sphincter EMG.Physiological features should therefore be taken into consideration when interpreting EMG resultsin clinical work.

\section{References}

1. Mannen T, Iwata M, Toyokura Y, Nagashima K (1977) Preservation of a certain motoneurone group of the sacral cord in amyotrophic lateral sclerosis: its clinical significance. See comment in PubMed Commons below J Neurol Neurosurg Psychiatry 40: 464-469.

2. Nakagawa S (1980) Onuf's nucleus of the sacral cord in a South American monkey (Saimiri): its location and bilateral cortical input from area 4 . See comment in PubMed Commons below Brain Res 191: 337-344.

3. Matzel KE, Schmidt RA, Tanagho EA (1990) Neuroanatomy of the striated muscular anal continence mechanism. Implications for the use of neurostimulation. See comment in PubMed Commons below Dis Colon Rectum 33: 666-673.

4. Gerrits PO, Sie JA, Holstege G (1997) Motoneuronal location of the external urethral and anal sphincters: a single and double labeling study in the male and female golden hamster. See comment in PubMed Commons below Neurosci Lett 226: 191-194.

5. Pullen AH, Tucker D, Martin JE (1997) Morphological and morphometric characterisation of Onuf's nucleus in the spinal cord in man. See comment in PubMed Commons below J Anat $191: 201-213$.

6. Bergmann M, Völpel M, Kuchelmeister K (1995) Onuf's nucleus is frequently involved in motor neuron disease/amyotrophic lateral sclerosis. See comment in PubMed Commons below J Neurol Sci 129: 141-146.

7. Forger NG, Breedlove SM (1986) Sexual dimorphism in human and canine spinal cord: role of early androgen. See comment in PubMed Commons below Proc Natl Acad Sci U S A 83: 7527-7531.

8. Polak K, Freeman LM (2010) Sex difference in Onuf's nucleus homologue in the Asian musk shrew. See comment in PubMed Commons below Brain Res 1346: 62-68.

9. Catala M (1999) [How sex dimorphism is established in the spinal nucleus of Onuf?]. See comment in PubMed Commons below Morphologie 83: 5-8.

10. Nandedkar SD, Barkhaus PE, Charles A (1995) Multi-motor unit action potential analysis (MMA) See comment in PubMed Commons below Muscle Nerve 18: 1155-1166.

11. Stålberg E, Falck B, Sonoo M, Stålberg S, Aström M (1995) Multi-MUP EMG analysis--a two year experience in daily clinical work. See comment in PubMed Commons below Electroencephalogr Clin Neurophysiol 97: 145-154.

12. Podnar S, Rodi Z, Lukanovic A, Trsinar B, Vodusek DB (1999) Standardization of anal sphincter EMG: technique of needle examination. See comment in PubMed Commons below Muscle Nerve 22: $400-403$.
13. Podnar S, Vodusek DB (2000) Standardization of anal sphincter electromyography: uniformity of the muscle. See comment in PubMed Commons below Muscle Nerve 23: 122-125.

14. Finsterer J, Mamoli B (1997) Satellite potentials as a measure of neuromuscular disorders. See comment in PubMed Commons below Muscle Nerve 20: 585-592.

15. Snooks SJ, Setchell M, Swash M, Henry MM (1984) Injury to innervation of pelvic floor sphincter musculature in childbirth. See comment in PubMed Commons below Lancet 2: 546-550.

16. Allen RE, Hosker GL, Smith AR, Warrell DW (1990) Pelvic floor damage and childbirth: a neurophysiological study. See comment in PubMed Commons below Br J Obstet Gynaecol 97: 770-779.

17. Sultan AH, Kamm MA, Hudson CN, Thomas JM, Bartram CI (1993) Anal-sphincter disruption during vaginal delivery. See comment in PubMed Commons below N Engl J Med 329: 1905-1911.

18. Chaliha C, Sultan AH, Bland JM, Monga AK, Stanton SL (2001) Anal function: effect of pregnancy and delivery. See comment in PubMed Commons below Am J Obstet Gynecol 185: 427-432.

19. Boyle DJ, Knowles CH, Murphy J, Bhan C, Williams NS, et al. (2012) The effects of age and childbirth on anal sphincter function and morphology in 999 symptomatic female patients with colorectal dysfunction. See comment in PubMed Commons below Dis Colon Rectum 55: 286-293.

20. Gregory WT, Lou JS, Stuyvesant A, Clark AL (2004) Quantitative electromyography of the anal sphincter after uncomplicated vaginal delivery. See comment in PubMed Commons below Obstet Gynecol 104: 327-335.

21. Lawson JO (1974) Pelvic anatomy. II. Anal canal and associated sphincters. See comment in PubMed Commons below Ann R Coll Surg Engl 54: 288-300.

22. Rasmussen OO (1994) Anorectal function. See comment in PubMed Commons below Dis Colon Rectum 37: 386-403.

23. Terao S, Sobue G, Hashizume Y, Li M, Inagaki T, et al. (1996) Agerelated changes in human spinal ventral horn cells with special reference to the loss of small neurons in the intermediate zone: a quantitative analysis. See comment in PubMed Commons below Acta Neuropathol 92: 109-114.

24. Tomlinson BE, Irving D (1977) The numbers of limb motor neurons in the human lumbosacral cord throughout life. See comment in PubMed Commons below J Neurol Sci 34: 213-219.

25. Ranson RN, Dodds AL, Smith MJ, Santer RM, Watson AH (2003) Ageassociated changes in the monoaminergic innervation of rat lumbosacral spinal cord. See comment in PubMed Commons below Brain Res 972: 149-158.

26. Laurberg S, Swash M (1989) Effects of aging on the anorectal sphincters and their innervation. See comment in PubMed Commons below Dis Colon Rectum 32: 737-742.

27. Podnar S, Vodusek DB, Stâlberg E (2000) Standardization of anal sphincter electromyography: normative data. See comment in PubMed Commons below Clin Neurophysiol 111: 2200-2207. 
Citation: Zhao L, Du H, Li B, Wu S, Lin N, et al. (2014) The Impact of Physiological Features on External Anal Sphincter Electromyography. J Neurol Neurophysiol 5: 227. doi:10.4172/2155-9562.1000227

Page 6 of 6

28. Brooke MH, Engel WK (1969) The histographic analysis of human muscle biopsies with regard to fiber types. 1. Adult male and female. See comment in PubMed Commons below Neurology 19: 221-233.

29. Tison F, Arne P, Sourgen C, Chrysostome V, Yeklef F (2000) The value of external anal sphincter electromyography for the diagnosis of multiple system atrophy. See comment in PubMed Commons below Mov Disord 15: $1148-1157$.
30. Winge K, Jennum P, Lokkegaard A, Werdelin L (2010) Anal sphincter EMG in the diagnosis of parkinsonian syndromes. See comment in PubMed Commons below Acta Neurol Scand 121: 198-203.

31. Linder J, Libelius R, Nordh E, Holmberg B, Stenlund H, et al. (2012) Anal sphincter electromyography in patients with newly diagnosed idiopathic parkinsonism. See comment in PubMed Commons below Acta Neurol Scand 126: 248-255. 